\title{
CAPITALISMO, COVID-19 E A CRISE ECONÔMICA: RUÍNA OU REVOLUÇÃO*
}

Fábio Coltro

\section{Introdução}

Apenas quatro meses atrás, ninguém tinha ouvido falar do vírus chamado covid19, o mundo funcionava dentro dos parâmetros usuais e os cidadãos viviam com a segurança produzida pela miragem do Capitalismo.

A construção do meio ambiente como um terreno exógeno e objetificável vem de longe, lançando as bases para numerosas teorias do desenvolvimento, com base no progresso humano apoiado no conhecimento científico e no controle e domínio da natureza. O dualismo Sociedade vs Natureza viria a ser a percepção segundo a qual os seres humanos representam a civilização, enquanto a natureza estaria em outro campo diferenciado, na natureza, onde outros deveriam ser estendidos sobre os indomáveis. (GERBEAU; AVALLONE, 2020)

$\mathrm{O}$ dualismo cartesiano não se limitou a permear o inconsciente coletivo das sociedades modernas, mas implicou que os vários ramos da ciência orientassem suas investigações com base nessa perspectiva. E qual foi o resultado? Um dos movimentos geopolíticos mais óbvios (e devastadores) apoiados por essa percepção o colonialismo. As mensagens civilizadoras legitimaram o controle das colônias na América, África, Ásia ou Oceania, afirmando estas como ambientes selvagens (incluindo suas populações) cujo controle permitiria o acesso desses territórios conquistados ao progresso, desde que se submetessem ao serviço das civilizações "desenvolvidas", que por sua vez, progrediram no cumprimento de uma determinada missão histórica. (GERBEAU; AVALLONE, 2020)

${ }^{*}$ DOI - 10.29388/978-65-86678-07-9-0-f.83-96 
O colonialismo não foi um movimento específico, limitado a um período histórico específico, mas um avanço na conquista da fronteira capitalista, abrangendo mais territórios e sujeitando mais populações ao processo de acumulação liderado pelas zonas centrais do sistema mundial. E aqui está a razão de ser do dualismo cartesiano: a construção da natureza como um campo separado dos seres humanos legitima sua exploração indispensável para garantir a acumulação capitalista. (GERBEAU; AVALLONE, 2020)

Para o antropólogo Viveiros de Castro, nunca foi possível separar a humanidade de ambiente, como não se trata de colocar um dentro e um fora, um ambientado e um "ambientante". Trata-se se dois modos - ao falar em Gaia e em humanidade, ou de qualquer outro avatar do sujeito - de começar um percurso; você pode começar por Gaia, ou pelo antropos, pelo húmus, humanus... E chegar-se ao outro lado sem o mínimo de descontinuidade, porque é um lado só, isso não quer dizer que não haja uma dobra, uma torção nessa figura de um lado só. (VIVEIROS DE CASTRO, 2014)

O problema do antropoceno é a aceleração do tempo, a transposição da cronotopia humana para a escala geológica. $\mathrm{O}$ antropoceno produz um descompasso, entre as subjetivações coletivas clássicas (a classe, a multidão, o povo, a nação) e a objetivação da espécie. A primeira crise - a crise do capitalismo tardio -, vem despertando, desde a virada do século, uma sequência de reações intermitentes e dispersas contra a mundialização neoliberal, contra o capitalismo financeiro e assim por diante e fez proliferar essas insurreições, todo um novo entusiasmo em relação à política coletiva de tipo minoritária insurrecional extraparlamentar, de massa, etc. A segunda crise - a crise da aceleração das mudanças ambientais -, que pôs em primeiro plano os efeitos deletérios dos fluxos materiais ou reais decorrentes do processo de acumulação do capital. Em certa medida a primeira manifestação é contra o neoliberalismo como máquina de financeirização do sistema, e a segunda é uma crise da produção real de $\mathrm{CO} 2$, de venenos e etc, e 
não uma crise do mercado. Ainda que nós saibamos que é a financeirização que puxa a segunda crise. (VIVEIROS DE CASTRO, 2014)

O processo de civilização envolveu sujeitar e localizar mais territórios e mais comunidades dentro da divisão global do trabalho, em um movimento indispensável para o sistema capitalista mundial, que exige a garantia de fluxos constantes de matérias-primas baratas, energia, comida e trabalho para manter processos de acumulação. Mas colocar os seres humanos para trabalhar a fim de explorar os vários recursos naturais não é "naturaP", é capitalismo, pois o objetivo final é obter mais-valia para garantir a acumulação dos atores que possuem os meios de produção. (GERBEAU; AVALLONE, 2020)

A teoria do colapso metabólico de Marx é uma maneira de olhar para as relações ecológicas ou metabólicas. Em particular, as complexas relações interdependentes da natureza e da sociedade, a partir de uma abordagem sistêmica muito antes do desenvolvimento da ecologia moderna e que de fato emergiram em bases semelhantes. (FOSTER, 2000)

Os processos de uso dos recursos naturais se intensificaram com a produção e a acumulação capitalistas, gerando rupturas na troca de seres humanos com a natureza, que Marx chamou de "o metabolismo universal da natureza". (FOSTER, 2005)

O ponto de vista da "ruptura metabólica" é na verdade um ponto de vista ecológico radical em relação às relações sociais capitalistas e é fundamental para entender a atual pandemia de coronavírus. (FOSTER, 2020)

Marx definiu o trabalho como uma mediação do intercâmbio metabólico entre seres humanos e natureza e analisou como diferentes "formas" históricas de trabalho alteraram todo o metabolismo social e natural. A teoria do metabolismo de Marx lidava com o problema da "ruptura metabólica"1 no capitalismo , inspirado por Justus von Liebig,

\footnotetext{
${ }^{1}$ A ruptura metabólica é a noção de Karl Marx da ruptura irreparável no processo interdependente do metabolismo social, isto é, a concepção chave de Marx das ten dências da crise ecológica no capitalismo. Marx teorizou uma ruptura na interação metabólica entre a humanidade e o resto da natureza que emana da produção capita-
} 
levando-o a se dedicar mais às ciências naturais a partir de 1868. - o conceito de metabolismo de Marx abordava diferentes maneiras de organizar o metabolismo trans-histórico ${ }^{2}$ entre a humanidade e a natureza. Ele reconheceu que vários sistemas de trabalho e propriedade em sociedades não europeias e pré-capitalistas empregaram processos distintos de metabolismo entre seres humanos e natureza. Além da brecha metabólica no sentido de Liebig, a perturbação do metabolismo social e natural também ocorreu sob a radical "transição" das comunidades tradicionais das aldeias após seu confronto com o capitalismo. (SAITO, 2017)

Marx reconheceu criticamente o poder destrutivo do capital e argumentou que as rupturas no metabolismo universal da natureza inevitavelmente minam as condições materiais para o desenvolvimento humano livre e sustentável. O caráter de roubo inerente ao desenvolvimento capitalista das forças produtivas não gera progresso que não leve a qualquer sociedade futura. (SAITO, 2016)

Para o sistema-mundo capitalista, é essencial explorar o que conhecemos como "natureza" e os seres humanos, pois ambos contribuem com o excedente ecológico, ou com mais valor, à espinha dorsal da acumulação. (MOORE, 2015)

Aqui devemos pensar nas diferenças entre o Antropoceno e o Capitaloceno. O Antropoceno proposto por Crutzen e aceito por grande parte da comunidade científica leva em consideração apenas o fato das mudanças geológicas atuais sem se questionar sobre sua ori-

lista e da crescente divisão entre cidade e o campo.

Segundo John Bellamy Foster, que cunhou o termo, a ruptura metabólica é o desen volvimento do trabalho anterior de Marx nos Manuscritos Econômicos e Filosóficos sobre o ser das espécies e a relação entre os seres humanos e a natureza. O metabolis mo é a análise madura de Marx da alienação da natureza e apresenta uma maneira mais sólida - e científica - de descrever o complexo e dinâmico intercâmbio entre seres humanos e natureza, resultante do trabalho humano.

${ }^{2} \mathrm{~A}$ ideia de trans-histórico é a qualidade de manter-se ao longo da história da huma nidade, não apenas dentro do quadro de referência de uma forma particular da sociedade em um estágio particular do desenvolvimento histórico. Uma entidade ou conceito que possui trans-historicidade é considerado trans-histórico.( JAMESON, 2013.) 
gem e responsabilizando a humanidade enquanto espécie e apostando na solução tecnológica. Já o Capitaloceno, uma forma de crítica ao Antropoceno, data e aponta os responsáveis por essas mudanças no globo. A abordagem do capitaloceno aponta para o surgimento do capitalismo e suas nefastas consequências como a origem e a responsabilidade são daqueles $1 \%$ da população que são sempre beneficiados com o Capitalismo.

Então, somos realmente seres exógenos à natureza? A teoria da ecologia-mundo sustenta que os seres humanos fazem parte da natureza tanto quanto o campo ou os animais, de modo que o correto seria falar sobre naturezas humanas e extra-humanas. Se não marcarmos essa separação arbitrária tanto em nossos pensamentos quanto em nossas investigações, podemos deduzir, então, por exemplo, que não estamos na era do antropoceno, pois os seres humanos não são igualmente culpados pelas mudanças climáticas. Estamos na era do capitaloceno, um momento histórico em que o capitalismo transformou completamente as naturezas, apropriando-as em busca da produção infinita e onde o aumento da temperatura global é causado por seu modelo e por aqueles que o apoiam, não para as comunidades humanas como um todo, uma vez que a grande maioria desempenha nele um papel sistêmico subordinado. (GERBEAU; AVALLONE, 2020)

O covid-19 nos coloca diante do espelho, ensinando-nos a falácia do dualismo cartesiano, porque somos mais uma parte da natureza e, portanto, somos vulneráveis aos patógenos que existem lá, mas também nos ensina que nosso cuidado é contrário à lógica do sistema capitalista, porque para nos proteger, devemos nos limitar e parar a produção, o trabalho, priorizando a vida. É hora de (re)construir a comunidade, privilegiar uma geração de valor não mercantil, com base no que é útil para o progresso e o cuidado da vida humana, mas também de natureza extra-humana. Os aplausos diários que dedicamos de nossos os terraços para o pessoal de saúde nos mostram que, ao parar as máquinas de produção, somos capazes de perceber o que tem valor real: solidariedade, atendimento, público. Em outras palavras, o que 
nos une. É muito cedo para conhecer as consequências globais que essa pandemia terá, mas, comparado à década anterior, marcada por austeridade e cortes, fica cada vez mais claro que isso exigirá uma mudança de paradigma, entendendo que o sistema que até agora tem governou o planeta, é contrário à vida que abriga. (GERBEAU; AVALLONE, 2020)

\section{Mas quem é responsável pela crise sanitária atual?}

Para todas as pessoas que não são negadoras do clima, há uma resposta fácil para essa pergunta: a humanidade. Quem, em sã consciência, poderia questionar a ideia de que a mudança climática é antropogênica (feita pelo homem). Não vivíamos no Antropoceno: a era do homem como força geológica? (MOORE, 2015)

Capitaloceno, pode parecer estranho quando dito. Isso, no entanto, tem pouco a ver com a palavra - é porque, sob a hegemonia burguesa, somos ensinados a olhar com suspeita para qualquer linguagem que dê nome ao sistema. Mas nomear o sistema, as formas de opressão e a lógica da exploração é o que os movimentos sociais emancipatórios sempre fazem. Os movimentos da justiça se desdobram através de novas ideias e novas linguagens. O poder de nomear uma injustiça canaliza pensamento e estratégia, algo dramaticamente subvalorizado pelos movimentos trabalhistas, anticoloniais e feministas ao longo do século XX.(MOORE, 2019)

Sabemos - historicamente e na atual crise - quem é o responsável. Eles têm nomes e endereços, começando pelos oito homens mais ricos do mundo, com mais riqueza do que os 3,6 bilhões de seres humanos na parte inferior. (MOORE, 2015)

É uma maneira de entender o capitalismo como um sistema histórico, geograficamente conectivo e padronizado. Nesta visão, o Capitaloceno é uma geopoética para entender o capitalismo como um mundo ecológico de poder e reprodução na rede da vida. (MOORE, 2019) 
Humanidade e Natureza não são apenas palavras, mas abstrações que foram tomadas como reais pelos impérios, estados modernizadores e capitalistas, com o objetivo de criar naturezas humanas e extra-humanas baratas de todos os tipos. Historicamente, a maioria dos humanos foi excluída em termos práticos da afiliação à Humanidade. Na história do capitalismo, em Antropos, há pouco espaço para quem não seja branco, masculino e burguês. Desde 1492, os super-ricos e seus aliados imperiais despojaram pessoas de cor, povos indígenas e praticamente todas as mulheres de sua humanidade, e os designaram para a natureza - assim, eles poderiam ser melhor transformados em oportunidades para gerar lucro. O resultado é que a cosmologia do homem e da natureza no antropoceno popular não é apenas analiticamente defeituosa, mas está implicada em histórias práticas de dominação. Quando o Antropoceno Popular se recusa a nomear as mudanças climáticas capitalogênicas, deixa de perceber que o problema não é o Homem e a Natureza, mas certos homens envolvidos na lucrativa dominação e destruição da maioria dos seres humanos e do resto da natureza. (MOORE, 2015)

Certamente, o capitalismo é um sistema de acumulação infinita de capital. Mas a tese do Capitaloceno aponta que, para entender a crise planetária hoje, precisamos considerar o capitalismo como um mundo ecológico de poder, produção e reprodução. Nessa perspectiva, os momentos "sociais" da dominação de classe moderna, da supremacia branca e do patriarcado estão intimamente ligados a projetos ambientais voltados à acumulação incessante de capital. Essencialmente, a grande inovação do capitalismo, desde suas origens após 1492, foi inventar a prática de apropriação da natureza. Que a natureza não era apenas uma ideia, mas uma realidade territorial e cultural que trancava e vigiava as mulheres, colonizava os povos e as redes de vida extrahumana. Como as redes da vida resistem à padronização, aceleração e homogeneização da maximização do lucro capitalista, o capitalismo nunca foi meramente econômico: a dominação cultural e a força po- 
lítica tornaram possível a devastação capitalogênica das naturezas humanas e extra, sempre humano. (MOORE, 2015)

Esses instantâneos da história do capitalismo nos dizem que esse sistema peculiar sempre dependeu das fronteiras das naturezas baratas - naturezas não comercializadas cujo trabalho pode ser apropriado de forma gratuita ou a baixo custo por meio de violência, dominação cultural e mercados. Essas fronteiras sempre foram cruciais porque o capitalismo é o sistema mais prodigiosamente inútil já criado. Isso explica a extraordinária extroversão do capitalismo. Para sobreviver, ela teve que cercar o planeta simultaneamente como uma fonte da Natureza Barata e como um depósito de lixo planetário. Ambas as fronteiras, que permitem uma redução radical dos custos e, portanto, a maximização dos lucros, estão agora se fechando. Por um lado, o Barato é um relacionamento sujeito à exaustão - trabalhadores e camponeses se rebelam e resistem, as minas estão esgotadas, a fertilidade do solo é corroída. Por outro lado, a cobertura do capitalismo da atmosfera planetária e de outros bens comuns por seus detritos ultrapassou um limiar crítico. A mudança climática de época é a expressão mais dramática desse ponto de virada, onde descobrimos que a crescente toxificação global está desestabilizando cada vez mais as realizações de época do capitalismo e, acima de tudo, de seu regime de comida barata. Essas duas estratégias, Natureza Barata e Lixo Barato, estão cada vez mais esgotadas, à medida que a geografia da produção e do lucro da vida entra em uma fase mórbida. A pandemia do coronavirus mudando tudo. A ecologia-mundo do capitalismo está passando por uma inversão de época - ou melhor, uma implosão - já que as naturezas não são mais baratas e começam a montar uma resistência cada vez mais eficaz. As redes da vida em todos os lugares estão desafiando estratégias de redução de custos de capital e se tornando uma realidade maximizadora de custos para o capital.(MOORE, 2019)

Podemos pensar que o futuro nos reserva, de forma otimista, o que Marx passou a reconhecer a "vitalidade natural" das comunas précapitalistas existentes que poderiam servir como uma base social para 
revoluções futuras. As contradições do capitalismo se manifestam mais claramente quando as forças violentas do desenvolvimento econômico confrontam a vitalidade natural de outras formações sociais fora do capitalismo. (SAITO, 2016)

\section{O capital pode lucrar mesmo com desastres ambientais.}

Marx percebeu que o desenvolvimento tecnológico é organizado como "forças produtivas do capital", que levam à realização plena de aspectos negativos das tecnologias, de modo que não podem funcionar como fundamento material para a sociedade socialista.(SAITO, 2017)o capital pode continuar a lucrar com a atual crise ecológica ao inventar novas oportunidades de negócios, como geoengenharia, OGM e, claro, a pandemia de coronavirus ${ }^{3}$. Assim, os limites naturais não levam ao colapso do sistema capitalista. (SAITO, 2017)

o capitalismo é muito mais elástico, pois é provável que este sistema social sobreviva e continue a acumular capital, mesmo que a atual crise ecológica se aprofunde para destruir o planeta inteiro e produzir um proletariado ambiental de massa em todo o mundo.(SAITO, 2017)

A luta pela vida durante a pandemia de coronavirus inclui claramente um componente da luta de classes. (SAITO, 2020). As pessoas ricas provavelmente sobreviveriam, enquanto os pobres são muito mais vulneráveis ao covid-19, embora sejam muito menos responsáveis pela crise do que os ricos. Os pobres não possuem meios tecnológicos e financeiros eficazes para se protegerem das consequências catastróficas dessa pandemia. É por isso que um compromisso sério com a questão ambiental exige simultaneamente uma luta consciente contra o capitalismo.

Rob Wallace (et al, 2020) explicou que a origem do CONVID19 e outros vírus recentes tem sido a penetração mais intensa do agronegócio nos sistemas naturais, o que criou fissuras nos ecossistemas e

${ }^{3}$ Ver: https://brasil.elpais.com/opiniao/2020-04-30/bolsonaro-sob-a-lupa.html 
entre as espécies, causando o surgimento de pandemias globais. Em "Notas sobre um novo coronavírus", Wallace argumenta que a solução estrutural é a construção de "um ecossocialismo que atenua a lacuna metabólica entre ecologia e economia, entre urbano, rural e selvagem. Evitando assim o surgimento de patógenos piores desse tipo".(WALLACE et al, 2020)

Mais de um século atrás, o zoólogo Ray Lankester, escreveu que num esforço ambicioso para produzir um grande número de animais e plantas, o homem acumulou um grande número de espécies de maneira não natural em campos e fazendas e também concentrou multidões não naturais nas cidades. $\mathrm{O}$ resultado é o crescimento de novas doenças associadas a parasitas, vírus e bactérias Para Lankester, um crítico agudo do capital, o problema estáestava nos "mercados" e nos "comerciantes de finanças cosmopolitas".(LANKESTER, 1905)

Hoje, no Capitaloceno, não há dúvida de que o capitalismo está criando fissuras antropogênicas nas espécies, nos ecossistemas e na atmosfera, gerando uma crise socioecológica, que em última instância se deve às contradições do sistema de acumulação. O regime capitalista cria grandes disparidades de classe e imperiais, causando perigos ambientais aos mais pobres e vulneráveis, enquanto os ricos são relativamente seguros.(FOSTER, 2020)

Seria um erro grave NÃO entender que a crise ecológica planetária e a crise da economia capitalista global são elementos dialeticamente interconectados de uma crise estrutural de capital que define nosso tempo.(FOSTER, 2020)

\section{Que trabalho os capitais querem?}

Para o sociólogo Ricardo Antunes, estamos a beira de um colapso social profundo, o que não é novidade. No Brasil, o neoliberalismo é devastador e as empresas não vão pagar os trabalhadores que não trabalharem, os aplicativos todos não vão pagar porque os trabalhadores são prestadores de serviço. A previdência estará fechada para eles e 
a saúde pública vai depender dos atendimentos e dos leitos existentes na precária situação da saúde pública que foi destruída pelos governos neoliberais do Brasil.(ANTUNES, 2020)

Antunes afirma que: "Chega uma hora que a saída é ao modo do Bacurau, entende? Não estou antecipando nada. Mas eu duvido que uma sociedade pode destroçar tanto assim, ilimitadamente e eternamente" (ANTUNES, 2020).

Como vimos a pandemia do coronavírus não é um elemento desconectado do sistema de metabolismo antissocial do capital de caráter profundamente destrutivo, assim, o capital só pode se ampliar destruindo e é por isso que ele destrói a força humana de trabalho em proporções monumentais, destrói a natureza de modo visceral. (ANTUNES, 2020)

Há um agravamento disto tudo no contexto da pandemia, que não é um efeito "naturaP' sem conexões com o sistema de metabolismo social do capital. $O$ coronavírus é a expressão clara desta tragédia de um sistema que é letal em relação ao trabalho, à natureza, à liberdade substantiva entre os gêneros, as raças, as etnias e tantas outras dimensões. (ANTUNES, 2020)

Que trabalho os capitais querem? Um trabalho cada vez mais desprovido de direitos, mais informal, funcionando como um apêndice de uma máquina que domina o mundo. Por isso a situação pandêmica é trágica. Ao mesmo tempo que os trabalhadores e trabalhadoras, como todo cidadão com o mínimo de dignidade, deveriam ficar em isolamento social para evitar a letalidade do capitalismo pandêmico, se ficarem em casa estão condenados a morrerem de fome. Então vão trabalhar onde é possível trabalhar.(ANTUNES, 2020)

A questão da natureza é outra coisa importante: “A destruição nos coloca, como István Mészáros disse anos atrás, lembrando Rosa Luxemburgo, que o futuro imediato nos coloca a questão do socialismo ou barbárie, se tivermos sorte. Esta adição de Mészáros é espetacularmente atual: corremos o risco de não termos nem barbárie porque estamos num patamar mais profundo, que está num degrau inferior e 
mais abaixo do que a barbárie. A questão da natureza evidencia isso". (ANTUNES, 2020) Para mim, barbárie é o agora. Não corremos o risco de cair na barbárie porque já estamos nela, olha o tanto de negro e pobre que morre no Brasil todo dia.

Portanto, é necessário que reinventemos outro sistema de metabolismo social contrário aos imperativos destrutivos do sistema de capital. Isso vale para quando pensamos na questão da liberdade substantiva, da emancipação efetiva entre os gêneros. Isso é vital quando se pensa na luta contra o racismo, contra a xenofobia, contra a homofobia, contra o sexicismo, contra a cultura visceral e indigente da ignorância. (ANTUNES, 2020)

Afirma Antunes (2020):

Temos hoje o mundo dos ignorantes; é como se cultuar a ignorância fosse o top. Isso mostra a indigência do mundo em que estamos. Só sairemos disso através das lutas das periferias, das comunidades indígenas, da classe trabalhadora masculina, feminina, branca, negra, indígena, da juventude, do movimento dos negros, da revolução feminista - há uma revolução feminista em curso e é vital que ela adira, como muitos dos seus setores vêm fazendo, a uma luta contra a opressão masculina, contra a opressão de gênero e contra as formas de opressão e dominação do capital. Estamos num momento em que o imperativo é reinventar outro modo de vida e a questão vital do nosso tempo é: temos que lutar pela vida e não pelo lucro.

De fato, é vital que a luta contra o capital adira as pautas do movimento feminista, indígena, LGBTTQ ... tem que inverter essa ordem, não é o feminismo que tem $\mathrm{q}$ aderir à luta de classe, a luta de classe é que tem que aderir as pautas feministas. A revolução, de fato, será feminista, ou não será!!!

Ficar tudo como sempre ("Bussiness as usual') - com sistemas de dominância de classe e produção e tudo o mais - é algo que nunca sobrevive a grandes perturbações dessa pandemia.(MOORE, 2019) 
O sistema capitalista falhou (ou será que não?). Uma ruptura revolucionária será necessária não apenas com o capitalismo em sentido estrito, mas também com toda a estrutura do imperialismo colonizatório, que é o campo em que a acumulação opera hoje. A sociedade terá que ser reconstituída em uma base radicalmente nova. A escolha diante de nós é gritante: ruína ou revolução.

\section{Referências}

ANTUNES, Ricardo. $1^{\circ}$ de maio em tempos de pandemia: a mutação do capitalismo e a degradação do trabalho. Entrevistas especiais com Ricardo Antunes, Clemente Lúcio e José Dari Krein. Instituto Humanitas Unisinos - IHU, 2020. Disponível em: <http://www.ihu.unisinos.br/159-noticias/entrevistas/598528-1-de-maio-em-tempos-depandemia-a-mutacao-do-capitalismo-e-a-degradacao-do-trabalhoentrevistas-especiais-com-ricardo-antunes-clemente-lucio-e-dari-

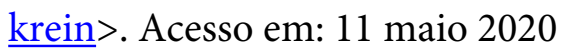

FOSTER, John Bellamy. A ecologia de Marx: materialismo e natureza. Editora Record, 2005.

. Catastrophe capitalism: climate change, COVID-19, and economic crisis. Monthly Review online. Disponível em: $<\underline{\text { https://mronli- }}$ ne.org/2020/04/01/catastrophe-capitalism-climate-change-covid-19and-economic-crisis/>. Acesso em: 11 maio 2020

. E. Ray Lankester, Ecological Materialist: An Introduction to Lankester's “The Effacement of Nature by Man”. Organization \& Environment, v. 13, n. 2, p. 233-235, 2000.

. The Return of Nature: Socialism and Ecology. Monthly Review Press, 2020.

GERBEAU, Yoan Molinero; AVALLONE, Gennaro. Ecología-mundo, un nuevo paradigma para el estudio de las migraciones internaciona- 
les. Empiria: Revista de metodología de ciencias sociales, n. 46, p. 2344, 2020.

JAMESON, Fredric. The political unconscious: Narrative as a socially symbolic act. Routledge, 2013.

LANKESTER, Edwin Ray. Nature and man. Clarendon Press, 1905.

MOORE, Jason W. Capitalism in the Web of Life: Ecology and the Accumulation of Capital. Verso Books, 2015.

. World-ecology: a global conversation. Sociologia urbana e rurale, 2019.

SAITO, Kohei. Karl Marx's ecosocialism: Capital, nature, and the unfinished critique of political economy. NYU Press, 2017. . Karl Marx's Ecosocialism: Capital, Nature, and the Unfinished Critique of Political Economy. Monthly Review, v. 72, 2020. . Marx's ecological notebooks. Monthly Review, v. 67, n. 9, p. 25-42, 2016.

VIVEIROS DE CASTRO, Eduardo. A revolução faz o bom tempo. In: Conferência no Colóquio Os Mil Nomes de Gaia. Rio de Janeiro: Casa Rui Barbosa. 2014.

WALLACE, Rob et al. COVID-19 and Circuits of Capital. Monthly Review, v. 72, 2020. 